\title{
ANALISIS FAKTOR RISIKO TERHADAP KETERLAMBATAN PROYEK KONSTRUKSI THE HIMANA CONDOTEL
}

\author{
Ni Made Sintya Rani ${ }^{1)}$ dan Ni Kadek Sri Ebtha Yuni ${ }^{1)}$ \\ 1) Jurusan Teknik Sipil, Politeknik Negeri Bali, Badung, Bali \\ sintyarani@pnb.ac.id
}

\begin{abstract}
One of the problems in construction activities is the risk of delays in the construction project. In The Himana Condotel project, several obstacles make some of the work not on the schedule. We analyze risk factors for delays to find out the dominan risk dan the solution. This research method uses a quantitative descriptive method and using questionnaires and interviews. The respondents were taken based on the criteria that are the respondent who has the important position at the Himana Condotel Project. From the data, we can specify the frequency and consequences occur risk that uses semantic differential scale in the questionnaire, that obtained the dominant risk factor based on the risk rating table with the highest risk level. After we get the dominant risk factors and the risk description, then we can determine the mitigation action that we can suggest. From the analysis, we get 5 variable risk factors for delay from The Himana Condotel project that is planning aspects, employment documents and contracts aspects, implementation aspects, resource aspects, and environmental aspects. Of the five aspects, the risk descriptions are described as 48. The dominant risk is obtained based on the percentage of the risk level, the risk level is obtained with a value of $36 \%$. From the five aspects of the risk factors for delays, all of them have high risks and 17 descriptions of risks that have a high-risk level. The suggested matters for the dominant risk mitigation to be carried out are more coordination between the parties involved, the preparation of schedule and planning in more detail, technical implementation in the fields especially for $B Q$, contract, work planning and terms to get more attention and increase the accuracy of the implementation of work as planned.
\end{abstract}

Keywords: risk, dominant, mitigation, schedule 


\begin{abstract}
ABSTRAK
Salah satu masalah dalam kegiatan konstruksi adalah risiko keterlambatan proyek konstruksi. Proyek The Himana Condotel terjadi beberapa kendala yang mengakibatkan beberapa pelaksanaan pekerjaannya tidak sesuai dengan schedule. Dilakukan analysis faktor-faktor risiko terhadap keterlambatan untuk mengetahui faktor risiko dominan dan solusinya. Metode Penelitian ini menggunakan metode deskriptif kuantitatif dan menggunakan kuesioner dan wawancara. Responden diambil berdasarkan kriteria yaitu responden memegang peranan penting pada proyek konstruksi The Himana Condotel. Dari data tersebut ditentukan frekuensi dan konsekuensi terjadinya risiko dengan menggunakan semantic differential scale pada kuesioner, diperoleh faktor risiko dominan berdasarkan table risk rating dengan level risiko tertinggi. Setelah diperoleh variable faktor risiko dominan dan uraian risikonya, maka dapat ditentukan tindakan mitigasi yang dapat disarankan. Dari hasil analisis diperoleh 5 variabel faktor risiko keterlambatan proyek The Himana Condotel yaitu dari aspek perencanaan, aspek Dokumen pekerjaan dan kontrak, aspek pelaksanaan, aspek sumber daya dan aspek lingkungan. Dari kelima aspek tersebut diuraikan menjadi 48 uraian risiko. Risiko dominan yang diperoleh berdasarkan presentase tingkat risiko diperoleh tingkat risiko tinggi dengan nilai 36\%. Dari kelima aspek variable faktor risiko keterlambatan seluruhnya terdapat risiko tinggi dan uraian risiko yang memiliki tingkat risiko tinggi ada sebanyak 17 uraian risiko. Hal-hal yang disarankan untuk mitigasi risiko dominan yang dilakukan adalah dengan lebih banyak berkoordinasi antara pihak-pihak yang terkait, penyusunan penjadwalan dan perencanaan secara lebih terperinci, teknis pelaksanaan dilapangan khususnya dokumen pekerjaan baik BQ, kontrak, RKS lebih diperhatikan, meningkatkan ketepatan pelaksanaan pekerjaan sesuai dengan yang telah direncanakan.
\end{abstract}

Kata kunci: risiko, dominan, mitigasi, jadwal 


\section{PENDAHULUAN}

Proyek konstruksi adalah suatu rangkaian kegiatan yang umumnya berjangka waktu pendek dan pelaksanaanya hanya dilakukan satu kali. Karakteristik proyek konstruksi dapat dipandang dalam tiga dimensi yaitu unik, melibatkan sejumlah sumber daya dan membutuhkan organisasi. Proses penyelesaian sebuah proyek kosntruksi harus berpegang pada tiga kendala (triple constrain) yaitu sesuai dengan spesifikasi yang ditentukan, sesuai dengan time schedule dan sesuai dengan biaya yang direncanakan. Karena merupakan kegiatan dengan proses yang panjang maka didalam kegiatan proyek kosntruksi banyak ditemukan masalah yang harus diselesaikan (Ervianto, 2005). Salah satu masalah yang muncul dalam kegiatan konstruksi adalah risiko keterlambatan proyek konstruksi. Menurut Husen (2011), risiko proyek dalam manajemen risiko adalah efek kumulasi dari peluang kejadian yang tidak pasti, yang mempengaruhi sasaran dan tujuan proyek. Risiko proyek dikonotasikan negatif yaitu sebagai kemungkinan kerugian dan bersifat tidak menguntungkan bagi proyek, salah satu risiko proyek adalah keterlambatan pelaksanaan pekerjaan. Dampak yang dapat ditimbulkan akibat keterlambatan pelaksanaan proyek mulai dari peningkatan biaya proyek, penurunan keuntungan yang seharusnya diperoleh dan penambahan waktu pelaksanaan yang mengakibatkan terjadinya konflik antara kedua belah pihak.

Penelitian oleh Wirawan, Sudarsana, \& Purbawijaya (2015) pada proyek Quinci Villas dan Putri Naga Komodo menyatakan bahwa risiko teridentifikasi sebanyak 25 risiko yang terdiri dari 1 risiko (4\%) medium risk, 6 risiko (24\%) high risk, 18 risiko (72 \%) extreme risk. Penelitian manajemen risiko pada proyek konstruksi di pemerintah Kabupaten Jembrana oleh Norken, Astana, \& Manuasri (2012) menunjukan 5 risiko tidak dapat diterima, 43 risiko tidak diharapkan, 18 risiko dapat diterima dan 5 risiko dapat diabaikan. Hasil penelitian pada pelaksanaan pembangunan system pengolahan air limbah terpusat Kota Denpasar tahap II diperoleh 8 risiko (11.27 $\%)$ unacceptable, 50 risiko (70.42 \%) undesirable, 9 risiko (12.68\%) acceptable dan 4 risiko $(5.63 \%)$ negligible (Putera, Harmayani, \& Putra, 2019). Sama halnya dengan penelitian oleh Nurlela \& Suprapto (2014) mengenai identifikasi dan analisis menajemen risiko pada proyek pembangunan infrastruktur bangunan gedung bertingkat diperoleh hasil 18 kejadian risiko dan 12 penyebab risiko. Pada penelitian oleh Rumimper, Sompie, \& Sumajouw (2015) pada proyek konstruksi 
perumahan di Kabupaten Minahasa Utara diperoleh hasil 3 risiko high risk, 1 risiko significant risk, 5 risiko medium risk dan 1 risiko low risk.. Pada penelitian oleh Sukirno (2015) tentang analisis risiko waktu di proyek konstruksi dengan studi kasus proyek Ampuh Pressure Maintenance di Duri, Riau pun diidentifikasi 5 risiko paling dominan penyebab keterlambatan yaitu SDM, Peralatan, Pengadaan material, perubahan desain dan spesifikasi serta kualitas dan pengalaman pengawas. Dari hasil studi yang pernah dilakukan langkahlangkah pengendalian risiko yang dapat dilakukan adalah dengan cara mengurangi frekuensi dan konsekuensi risiko.

Kabupaten Badung merupakan salah satu kabupaten di Bali dengan tingkat pembangunan yang pesat. Salah satu proyek pembangunan gedung di Kabupaten Badung adalah The Himana Condotel oleh kontraktor PT. Jaya Kusuma Sarana Bali. The Himana Condotel saat ini telah memasuki tahap pekerjaan arsitektur dimana pembangunan The Himana Condotel direncanakan dikerjakan selama 18 bulan, namun pada pelaksanaanya terjadi beberapa kendala yang mengakibatkan beberapa pelaksanaan pekerjaannya menjadi tidak sesuai dengan schedule. Sehubungan dengan hal tersebut maka dilakukan analisis faktor-faktor risiko terhadap keterlambatan proyek konstruksi The Himana Condotel. Pada penelitian ini akan dilakukan penyebaran kuesioner kepada pihak kontraktor dan juga akan dilaksanakan observasi secara langsung dilapangan.

Tujuan dari penelitian ini adalah untuk mengetahui faktor-faktor risiko penyebab keterlambatan pelaksanaan proyek konstruksi The Himana Condotel. Dari faktor-faktor risiko yang diperoleh akan dicari faktor risiko dominan dan solusi rencana tindakan mitigasi yang dapat dilakukan agar pelaksanaan proyek konstruksi dapat berjalan dengan baik dan lancar.

\section{KAJIAN PUSTAKA}

\subsection{Keterlambatan}

Penyebab keterlambatan waktu pelaksanaan proyek dapat dikategorikan dalam 3 kelompok (Kraiem dan Dickman, dalam Proboyo, 1999):

1. Keterlambatan yang layak mendapatkan ganti rugi (compensable delay), yakni keterlambatan yang disebabkan oleh tindakan, kelalaian, atau kesalahan pemilik proyek.

2. Keterlambatan yang tidak dapat dimaafkan (non-excuseable delay) yakni keterlambatan yang 
disebabkan oleh tindakan, kelalaian, atau kesalahan pemilik proyek.

3. Keterlambatan yang dapat dimaafkan (excuseable delay) yakni keterlambatan yang disebabkan oleh kejadiankejadian diluar kendali baik pemilik maupun kontraktor.

\subsection{Manajemen Risiko}

Manajemen risiko merupakan pendekatan terorganisasi untuk menemukan risiko-risiko yang potensial sehingga dapat mengurangi terjadinya halhal diluar dugaan. Manajemen risiko harus dilakukan sedini mungkin dengan didukung informasi tersebut. Prosesnya merupakan tindak preventif dimana kondisi usaha sesungguhnya dapat menjadi jelas sebelum terlambat dan dapat terhindar dari kegagalan yang lebih besar (Kerzner, 2001).

Flanagan \& Norman mendefinisikan manajemen risiko adalah cara untuk mengidentifikasi dan mengukur seluruh risiko dalam suatu proyek atau bisnis sehingga dapat diambil keputusan bagaimana mengelola risiko tersebut. Tujuan manajemen risiko adalah mengidentifikasi dan mengkualifikasi seluruh risiko yang dihadapi proyek sehingga dapat diambil keputusan yang tepat bagaimana cara menanganinya.

Manajemen risiko dilakukan atau dilaksanakan untuk mengurangi, menghindari, mengakomodasi suatu risiko melalui sejumlah kegiatan yang berurutan yaitu identifikasi risiko, klasifikasi Risiko, analisa risiko dan pengendalian risiko.

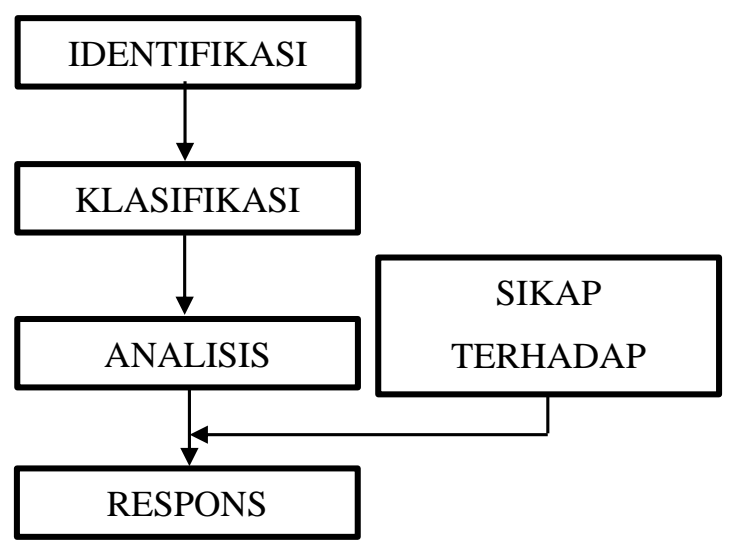

Gambar 1. Proses Manajemen Risiko

(Sumber: Flanagan \& Norman, 1993)

\subsubsection{Identifikasi risiko}

Identifikasi risiko adalah mengidentifikasi kondisi-kondisi ketidakpastian yang menimbulkan risiko, sumber risiko serta pengaruhnya. Pendekatan untuk mengidentifikasi risiko antara lain dengan cara checklist, brainstorming, analisis scenario serta wawancara dan kuesioner (Renaldhi, 2014). Untuk mengidentifikasi risiko, pertanyaan yang perlu dijawab adalah siapa yang terlibat dalam penilaian risiko dan mengapa, jenis risiko apa yang mempengaruhi suatu proyek. Sumber- 
sumber utama timbulnya risiko yang umum untuk setiap proyek konstruksi menurut Duffield dan Trigunarsyah (1999) dalam Labombang, 2011) adalah:

1. Fisik: kerugian atau kerusakan akibat kebakaran, gempa bumi, banjir, kecelakaan dan tanah longsor.

2. Lingkungan: kerusakan ekologi, polusi dan pengolahan limbah, penyelidikan keadaan masyarakat.

3. Perancangan: a) teknologi baru, aplikasi baru, ketahanan uji dan keselamatan, b) rincian, ketelitian dan kesesuaian spesifikasi, c) Risiko perancangan yang timbul dari pengukuran dan penyelidikan, d)kemungkinan perubahan terhadap rancangan yang telah disetujui, e) interaksi rancangan dengan metode konstruksi.

4. Logistik: a) kehilangan atau kerusakan material dan peralatan dalam perjalanan, b) ketersediaan sumber daya khusus, c) pemisah organisasi.

5. Keuangan: a) ketersediaan dana dan kecukupan asuransi, b) penyediaan aliran kas yang cukup, c) kehilangan akibat kontraktor, supplier, d) fluktuasi nilai tukar dan inflasi, e) perpajakan f) suku bunga, g) biaya pinjaman.

6. Perundangan-undangan yaitu perubahan disebabkan perundang-undangan atau pemerintah.

7. Keamanan property intelektual.

8. Hak atas tanah dan penggunaan.

9. Politik: a) risiko politik dinegara pemilik proyek, supplier dan kontraktor, peperangan, revolusi dan perubahan hokum, b) ketidakpastian dari kebijakan pemerintah.

10. Konstruksi: a)kelayakan metode konstruksi, keselamatan, b) hubungan industrial, c) tingkat perubahan dari rancangan awal, d)cuaca, e) kualitas dan ketersediaan manajemen dan supervise, f) kondisi yang tersembunyi.

11. Operasional: a) fluktiasi permintaan pasar erhadap produk dan jasa yang dihasilkan, b) kebutuhan perawatan, c) Keandalan, d) keselamatan pelaksanaan, e) ketersediaan pabrik, f ) manajemen. 
Jenis risiko yang terpenting bagi setiap pihak yang terlibat dalam sebuah proyek tergantung pada berbagai tahapan proyek dan peran serta tanggung jawab dari berbagai pihak.

\subsubsection{Analisis risiko}

Hasil identifikasi kondisi-kondisi ketidakpastian yang menimbulkan risiko harus dievaluasi dan dianalisis. Ada berbagai metode yang dapat digunakan sebagai tools, dengan penggunaannya yang disesuaikan dengan data maupun kondisi yang ada saat hendak melakukan analisis. Salah satu tools standar pengukuran yang dapat digunakan adalah skala pengukuran AS/NZS-4360:2004.

Analisis risiko merupakan suatu proses dari identifikasi dan penilaian (assessment). Analisis risiko yang dilakukan secara sistematis dapat membantu untuk mengidentifikasi, menilai dan merangking risiko secara jelas, memusatkan perhatian pada risiko utama, memperjelas batasan tentang batasan kerugian, meminimalkan potensi kerusakan apabila timbul keadaan yang paling jelek, mengontrol ketidakpastian dalam proyek, memperjelas dan menegaskan peran setiap orang/badan yang terlihat dalam manajemen risiko (Godfrey dalam Yuliana, 2017).
Risiko dapat dianalisis menggunakan penaksiran terhadap peluang terjadinya konsekuensi jika terjadi. Ketika Likelihood dan consequences telah ditetapkan, maka dilakukan evaluasi dan memperioritaskan risiko yang paling berpotensi untuk diatasi.

Berikut adalah skala untuk Likelihood dan consequences yang disajikan dalam Tabel 1 dan Tabel 2 (Renaldhi, 2014):

Tabel 1. Skala Likelihood

\begin{tabular}{|c|c|c|}
\hline Skala & Frekuensi Kejadian & Kategori \\
\hline 1 & $\begin{array}{c}\text { Probabilitas kejadian } \\
\text { kurang dari } 5 \%\end{array}$ & $\begin{array}{l}\text { Sangat jarang } \\
\text { terjadi (Rare) }\end{array}$ \\
\hline 2 & $\begin{array}{l}\text { Probabilitas kejadian } \\
\text { kurang dari } 5-25 \%\end{array}$ & $\begin{array}{l}\text { Jarang terjadi } \\
\text { (Unlikely) }\end{array}$ \\
\hline 3 & $\begin{array}{l}\text { Probabilitas kejadian } \\
\text { kurang dari } 25-50 \%\end{array}$ & $\begin{array}{l}\text { Sedang } \\
\text { (Possible) }\end{array}$ \\
\hline 4 & $\begin{array}{l}\text { Probabilitas kejadian } \\
\text { kurang dari } 50-75 \%\end{array}$ & $\begin{array}{l}\text { Sering terjadi } \\
\quad(\text { Likely })\end{array}$ \\
\hline 5 & $\begin{array}{c}\text { Probabilitas kejadian } \\
\text { lebih dari } 75 \%\end{array}$ & $\begin{array}{c}\text { Sangat sering } \\
\text { terjadi } \\
\text { (Almost } \\
\text { Certain) }\end{array}$ \\
\hline
\end{tabular}

Sumber: Renaldhi, 2014

Tabel 2. Skala Consequences

\begin{tabular}{|c|c|c|}
\hline Skala & $\begin{array}{l}\text { Dampak Risiko } \\
\text { terhadap keterlambatan }\end{array}$ & Kategori \\
\hline 1 & $\begin{array}{c}\text { Mengalami } \\
\text { keterlambatan 0-1 } \\
\text { bulan }\end{array}$ & $\begin{array}{l}\text { Sangat kecil } \\
\text { (Insignificant) }\end{array}$ \\
\hline 2 & $\begin{array}{c}\text { Mengalami } \\
\text { keterlambatan 1-2 } \\
\text { bulan }\end{array}$ & Kecil (Minor) \\
\hline 3 & $\begin{array}{c}\text { Mengalami } \\
\text { keterlambatan 2-3 } \\
\text { bulan }\end{array}$ & $\begin{array}{c}\text { Sedang } \\
\text { (Moderate) }\end{array}$ \\
\hline 4 & $\begin{array}{c}\text { Mengalami } \\
\text { keterlambatan 3-4 } \\
\text { bulan }\end{array}$ & $\begin{array}{l}\text { Tinggi } \\
\text { (Major) }\end{array}$ \\
\hline 5 & $\begin{array}{c}\text { Mengalami } \\
\underset{\text { keterlambatan }}{\text { bulan }}\end{array}$ & $\begin{array}{l}\text { Sangat tinggi } \\
\text { (Catasropic) }\end{array}$ \\
\hline
\end{tabular}

Sumber: Renaldhi, 2014 
Berikut adalah tingkat risiko (risk rating) dan juga tindakan yang dilakukan jika risiko tersebut terjadi. Tingkat risiko tersebut dibagi menjadi extreme risk, high risk, moderate risk dan low risk.

\section{Tabel 3. Risk Rating}

\begin{tabular}{|c|c|c|}
\hline Kode & Risk Rating & Action Required \\
\hline A & $\begin{array}{l}\text { Extreme } \\
\text { Risk }\end{array}$ & $\begin{array}{l}\text { Immediate action } \\
\text { required }\end{array}$ \\
\hline B & High Risk & $\begin{array}{l}\text { Senior Management } \\
\text { attention needed }\end{array}$ \\
\hline $\mathrm{C}$ & $\begin{array}{l}\text { Moderate } \\
\text { Risk }\end{array}$ & $\begin{array}{c}\text { Management } \\
\text { Responsibility must be } \\
\text { specified }\end{array}$ \\
\hline $\mathrm{D}$ & Low Risk & $\begin{array}{c}\text { Manage by routine } \\
\text { procedures }\end{array}$ \\
\hline
\end{tabular}

Sumber: Renaldhi, 2014

Setelah diperoleh Likelihood dan Consequences, maka langkah selanjutnya adalah membuat peta risiko yang dikelompokan berdasarkan dari data yang dianalisis. Berdasarkan risk rating dapat digunakan sebagai dasar untuk menyusun peta risiko sebagaimana tergambar pada tabel 4 dibawah ini.

Tabel 4. Peta Risiko

\begin{tabular}{|c|c|c|c|c|c|c|}
\hline \multirow{2}{*}{\multicolumn{2}{|c|}{ Peta Risiko }} & \multicolumn{5}{|c|}{ Consequences } \\
\hline & & 1 & 2 & 3 & 4 & 5 \\
\hline \multirow{5}{*}{ 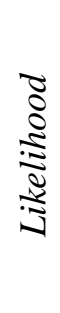 } & 5 & B & B & $\mathbf{A}$ & $\mathbf{A}$ & $\mathbf{A}$ \\
\hline & 4 & C & B & B & $\mathbf{A}$ & $\mathbf{A}$ \\
\hline & 3 & D & $\mathbf{C}$ & B & $\mathbf{A}$ & $\mathbf{A}$ \\
\hline & 2 & D & D & $\mathbf{C}$ & B & $\mathbf{A}$ \\
\hline & 1 & D & D & C & B & B \\
\hline
\end{tabular}

Sumber: Renaldhi, 2014

\subsubsection{Evaluasi risiko}

Pada tahap ini dilakukan perbandingan perkiraan level risiko terhadap kriteria yang ditetapkan dan dilakukan pertimbangan antara potensi keuntungan dan kerugian. Hasil dari evaluasi ini berupa daftar tingkat prioritas untuk tindakan lebih lanjut. Jika risiko pada kategori low, maka risiko dapat diterima dan ditangai secara minimal (Renaldhi, 2014).

\subsubsection{Mitigasi risiko}

Pada tahap ini dilakukan penentuan langkah-langkah yang dilakukan untuk menanggulangi risiko yang telah teridentifikasi. Tahapan ini merupakan upaya penanggulangan terhadap risiko yang digunakan untuk mengurangi probabilitas terjadinya risiko yang ada. Proses ini dilakukan setelah analisis risiko kualitatif. Mitigasi risiko harus sesuai dengan konteks risiko yang sedang dihadapi, sesuai dengan efektifitas biaya proyek, disetujui oleh seluruh pihak yang terlibat dalam proyek, serta menjadi tanggung jawab bagi pihak yang bersangkutan. Perencanaan bentuk mitigasi ini bertujuan untuk mengatur, mengeliminasi ataupun mengurangi risiko hingga batas yang ditentukan. Adanya pertimbangan dalam pemilihan alternatif tindakan mitigasi ini sangat diperlukan untuk menentukan langkah terbaik. Apabila 
bentuk mitigasi telah diimplementasikan, kemudian akan dilakukan monitoring secara berkelanjutan (Renaldhi, 2014).

\section{METODE PENELITIAN}

Metode Penelitian ini menggunakan metode deskriptif kuantitatif. Pada tahap pengumpulan data dilakukan dengan survey menggunakan kuesioner dan wawancara kepada pihak kontraktor pada proyek The Himana Condotel. Data yang dikumpulkan adalah data primer dan data sekunder. Data primer adalah data yang diperoleh melalui survey dengan menggunakan kuesioner dan wawancara, sedangkan data sekunder berupa data pendukung seperti RKS, Schedule pelaksanaan proyek, RAB dan Gambar. Penentuan sampel responden diambil berdasarkan purposive sampling yang dipilih berdasarkan kriteria yaitu responden memegang peranan penting pada proyek konstruksi The Himana Condotel. Responden pada penelitian ini adalah satu orang direksi, satu orang Project manager, satu orang site manager, dua orang supervisor dan dua orang quality control. Responden pada penelitian ini dominan memiliki pengalaman kerja tinggi dengan masa kerja antara 10-15 tahun yaitu sebanyak $57.14 \%$ dan ditinjau dari segi pendidikan terdapat $71.43 \%$ responden dengan pendidikan sarjana.
Setelah data diperoleh kemudian dilakukan analisa data guna memperoleh variable faktor risiko keterlambatan dan uraian risiko. Setelah faktor risiko dan uraian risiko ditentukan kemudian dicari faktor risiko dominan dengan terlebih dahulu menentukan frekuensi terjadinya risiko dan konsekuensi terjadinya risiko. Dari frekuensi risiko dan konsekuensi risiko diperoleh faktor risiko dominan berdasarkan table risk rating dengan nilai persentase level risiko tertinggi. Setelah diperoleh variable faktor risiko dominan dan uraian risikonya, maka dapat ditentukan tindakan mitigasi yang dapat disarankan untuk dilakukan guna menanggulangi risiko keterlambatan yang dapat terjadi.

\section{HASIL DAN PEMBAHASAN \\ 4.1 Analisis Faktor Risiko Keterlambatan}

Pada kuesioner yang digunakan pada penelitian ini dilakukan uji validitas dan reliabilitas. Pada kuesioner ini menggunakan semantic differential scale (lima tingkat), dimana tiap pernyataan diberi skor anatar $1-5$. Setelah dilakukan uji validitas dan reliabilitas diperoleh 5 variable risiko dengan 48 uraian risiko. Variabel faktor risiko keterlambatan pelaksanaan proyek konstruksi terlihat seperti pada Tabel 5 . 
Tabel 5. Faktor Risiko Keterlambatan Pelaksanaan Proyek

\begin{tabular}{|c|c|c|}
\hline No & $\begin{array}{l}\text { Faktor } \\
\text { Risiko }\end{array}$ & Uraian Risiko \\
\hline \multirow[t]{7}{*}{ A } & \multicolumn{2}{|c|}{ Aspek Perencanaan } \\
\hline & 1 & Penentuan durasi waktu kerja yang kurang jelas dan terperinci \\
\hline & 2 & Penetapan jadwal proyek yang terlalu ketat oleh owner \\
\hline & 3 & Tidak lengkapnya identifikasi jenis pekerjaan dan spesifikasi pekerjaan. \\
\hline & 4 & Rencana urutan kerja yang tidak tersusun dengan baik \\
\hline & 5 & Rencana kerja owner yang berubah-ubah \\
\hline & 6 & Metode pelaksanaan yang tidak tepat \\
\hline \multirow[t]{9}{*}{$\mathrm{B}$} & \multicolumn{2}{|c|}{ Aspek Dokumen Pekerjaan dan Kontrak } \\
\hline & 1 & Perencanaan gambar dan spesifikasi yang kurang jelas \\
\hline & 2 & Perubahan desain/spesifikasi pekerjaan pada waktu pelaksanaan \\
\hline & 3 & Proses permintaan dan persetujuan gambar kerja oleh owner \\
\hline & 4 & Adanya permintaan perubahan atas pekerjaan yanga telah selesai \\
\hline & 5 & Perubahan lingkup pekerjaan pada saat pelaksanaan \\
\hline & 6 & Proses pembuatan gambar kerja oleh kontraktor \\
\hline & 7 & Perbedaan pemahaman aturan pembuatan gambar kerja \\
\hline & 8 & Adanya pekerjaan tambahan \\
\hline \multirow[t]{11}{*}{$\mathrm{C}$} & \multicolumn{2}{|c|}{ Aspek Pelaksanaan } \\
\hline & 1 & Perbaikan pekerjaan yang tidak sesuai dengan spesifikasi \\
\hline & 2 & Perbedaan antara volume pekerjaan rencana dengan pelaksanaan \\
\hline & 3 & Pekerja mengabaikan prosedur K3 dalam pelaksanaan proyek / kecelakaan kerja \\
\hline & 4 & Keterbatasan wewenang personil/pemilik dalam pengambilan keputusan \\
\hline & 5 & Kualifikasi personil/pemilik yang tidak profesional di bidangnya \\
\hline & 6 & $\begin{array}{l}\text { Cara inspeksi dan kontrol pekerjaan yang membutuhkan waktu panjang dalam } \\
\text { pelaksanaannya }\end{array}$ \\
\hline & 7 & Kegagalan pemilik mengkoordinasikan penyerahan/penggunaan lahan \\
\hline & 8 & Keterlambatan akibat kesalahan pekerjaan kontraktor/sub kontraktor \\
\hline & 9 & Pendanaan kegiatan proyek yang tidak terencana dengan baik \\
\hline & 10 & Kualifikasi teknik dan manajerial yang buruk dari personil dalam organisasi kerja kontraktor \\
\hline \multirow[t]{13}{*}{$\mathrm{D}$} & \multicolumn{2}{|r|}{ Aspek Sumber Daya } \\
\hline & 1 & Keterlambatan dalam pengiriman material \\
\hline & 2 & Kehilangan pada material \\
\hline & 3 & Keterlambatan pembayaran termin oleh owner \\
\hline & 4 & Permasalahan pendanaan dari kantor pusat (internal) \\
\hline & 5 & Keterlambatan penyediaan alat/bahan dan lain-lain yang disediakan oleh owner \\
\hline & 6 & Penurunan produktiitas pekerja \\
\hline & 7 & Kekurangan kapasitas alat berat dari yang dibutuhkan \\
\hline & 8 & Kerusakan alat berat \\
\hline & 9 & Jumlah pekerja yang kurang memadai \\
\hline & 10 & Alat/peralatan kerja yang tidak memadai \\
\hline & 11 & Kurangnya keahlian dan keterampilan kerja pada pekerja \\
\hline & 12 & Tidak tersedianya bahan sesuai kebutuhan \\
\hline \multirow[t]{11}{*}{$\mathrm{E}$} & \multicolumn{2}{|c|}{ Aspek Lingkungan } \\
\hline & 1 & Inflasi yang mempengaruhi harga material \\
\hline & 2 & Keterlambatan yang disebabkan oleh cuaca \\
\hline & 3 & Kendala dalam pembebasan lahan \\
\hline & 4 & Kondisi atau lingungan sekitar proyek yang tidak sesuai dengan dugaan \\
\hline & 5 & Mobilisasi ke lokasi proyek yang sulit \\
\hline & 6 & Terjadi hal-hal tak terduga (bencana alam, kebakaran) \\
\hline & 7 & Adanya huru hara atau kerusuhan \\
\hline & 8 & Adanya kerusakan akibat pihak ketiga \\
\hline & 9 & Libur kegiatan adat diluar jadwal proyek \\
\hline & 10 & Perubahan situasi dan kebijakan politik pemerintah \\
\hline
\end{tabular}




\subsection{Faktor Risiko Dominan}

Berdasarkan data dari kuesioner

Faktor-faktor risiko yang telah disurvey, diperoleh modus frekuesi dan konsekuensi terjadinya risiko. Dari frekuensi dan konsekuensi yang diperoleh dapat ditentukan faktor risiko yang paling dominan terhadap risiko keterlambatan proyek The Himana Condotel.

\subsubsection{Modus frekuensi terjadinya risiko}

Persentase frekuensi terjadinya risiko berdasarkan hasil survey adalah sebesar 40 $\%$ untuk kategori sangat jarang, $31 \%$ untuk kategori jarang, $8 \%$ untuk kategori sedang, $17 \%$ untuk katgori sering dan $4 \%$ untuk kategori sangat sering. Dari persentase diatas dapat disimpulkan bahwa modus frekuensi terjadinya risiko berada pada skala sangat jarang.

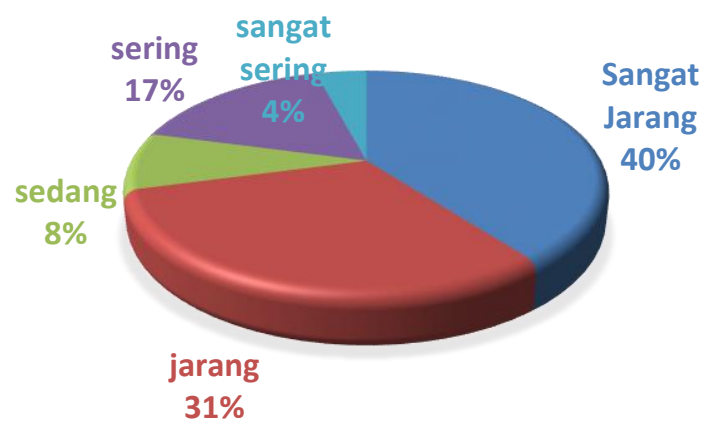

Gambar 2. Persentase Modus Frekuensi Terjadinya Risiko

\subsubsection{Modus konsekuensi terjadinya risiko}

Persentase konsekuensi terjadinya risiko berdasarkan hasil survey adalah sebesar $0 \%$ untuk kategori sangat kecil, 31
$\%$ untuk kategori kecil, $15 \%$ untuk kategori sedang, $44 \%$ untuk katgori tinggi dan $10 \%$ untuk kategori sangat tinggi. Dari persentase diatas dapat disimpulkan bahwa modus konsekuensi terjadinya risiko berada pada skala tinggi.

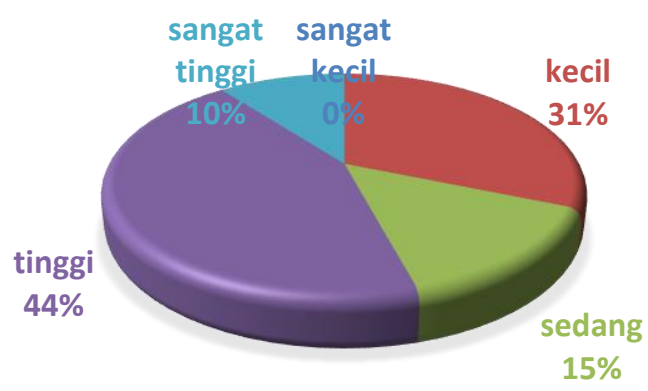

\section{Gambar 3. Persentase Modus Konsekuensi Terjadinya Risiko}

\subsubsection{Faktor risiko dominan}

Persentase Faktor tingkat risiko diperoleh berdasarkan table risk rating. Berdasarkan persentase tingkat risiko nilai yang diperoleh adalah risiko rendah dengan $29 \%$ (14 risiko), risiko menengah dengan $10 \%$ (5 risiko), risiko tinggi dengan $36 \%$ (17 risiko) dan risiko ekstrim $25 \%$ (12 risiko).

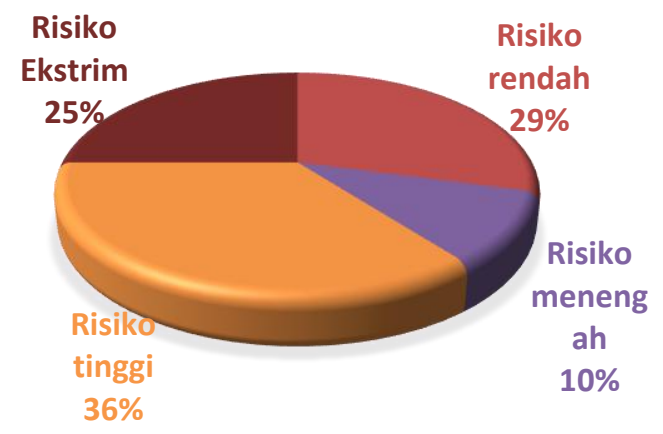

Gambar 4. Persentase Tingkat Risiko 
Risiko paling dominan adalah tingkat risiko tinggi dengan variable faktor risiko dapat dilihat pada Tabel 6 .

\subsection{Mitigasi Risiko Dominan}

Tindakan mitigasi risiko merupakan tindakan dari penanggulangan terhadap risiko dominan yang terjadi selama pelaksanaan proyek konstruksi. Tindakan penanggulangan sebatas tindakan meminimalisir dampak dari risiko yang mungkin akan terjadi. Mitigasi risiko pada penelitian ini diperoleh dari kuesioner dan wawancara kepada pihak kontraktor. Tindakan mitigasi yang dilakukan seperti pada Tabel 7.

Tabel 6. Faktor Risiko Dominan Keterlambatan Pelaksanaan Proyek

\begin{tabular}{|c|c|c|}
\hline No & $\begin{array}{l}\text { Faktor } \\
\text { Risiko }\end{array}$ & Uraian Risiko \\
\hline \multirow[t]{2}{*}{ A } & \multicolumn{2}{|c|}{ Aspek Perencanaan } \\
\hline & 1 & Penentuan durasi waktu kerja yang kurang jelas dan terperinci \\
\hline \multirow[t]{5}{*}{ B } & \multicolumn{2}{|c|}{ Aspek Dokumen Pekerjaan dan Kontrak } \\
\hline & 1 & Perencanaan gambar dan spesifikasi yang kurang jelas \\
\hline & 2 & Proses permintaan dan persetujuan gambar kerja oleh owner \\
\hline & 3 & Adanya permintaan perubahan atas pekerjaan yanga telah selesai \\
\hline & 4 & Adanya pekerjaan Tambahan \\
\hline \multirow[t]{5}{*}{$\mathrm{C}$} & \multicolumn{2}{|c|}{ Aspek Pelaksanaan } \\
\hline & 1 & Perbaikan pekerjaan yang tidak sesuai dengan spesifikasi \\
\hline & 2 & Perbedaan antara volume pekerjaan rencana dengan pelaksanaan \\
\hline & 3 & Pekerja mengabaikan prosedur K3 dalam pelaksanaan proyek / kecelakaan kerja \\
\hline & 4 & $\begin{array}{l}\text { Kualifikasi teknik dan manajerial yang buruk dari personil dalam organisasi kerja } \\
\text { kontraktor }\end{array}$ \\
\hline \multirow[t]{6}{*}{$\mathrm{D}$} & \multicolumn{2}{|c|}{ Aspek Sumber Daya } \\
\hline & 1 & Keterlambatan pembayaran termin oleh owner \\
\hline & 2 & Jumlah pekerja yang kurang memadai \\
\hline & 3 & Alat/peralatan kerja yang tidak memadai \\
\hline & 4 & Kurangnya keahlian dan keterampilan kerja pada pekerja \\
\hline & 5 & Tidak tersedianya bahan sesuai kebutuhan \\
\hline \multirow[t]{4}{*}{$\mathrm{E}$} & \multicolumn{2}{|c|}{ Aspek Lingkungan } \\
\hline & 1 & Terjadinya hal-hal yang tidak terduga (bencana alam, kebakaran) \\
\hline & 2 & Adanya huru-hara atau kerusuhan \\
\hline & 3 & libur kegiatan adat diluar jadwal proyek \\
\hline
\end{tabular}


Tabel 7. Mitigasi Risiko Dominan Keterlambatan Pelaksanaan Proyek

$\begin{array}{lll}\text { Faktor } & \text { Uraian Risiko } & \text { Tindakan Mitigasi } \\ \text { Risiko }\end{array}$

A Aspek Perencanaan

1 Penentuan durasi waktu kerja yang kurang jelas dan terperinci

B Aspek Dokumen Pekerjaan dan Kontrak

1 Perencanaan gambar dan spesifikasi yang kurang jelas

2 proses permintaan dan persetujuan gambar kerja oleh owner

3 adanya permintaan perubahan atas pekerjaan yanga telah selesai

Penentuan alokasi waktu kerja pada setiap pekerjaan lebih terperinci dan jelas.

Perbaikan perencanaan oleh konsultan perencana dan manajemen kontraktor

Pembuatan SOP pengajuan gambar kepada owner

Addendum kontrak, melakukan penjadwalan ulang dan mengecek kembali BQ

4 Adanya pekerjaan Tambahan

C Aspek Pelaksanaan

1 Perbaikan pekerjaan yang tidak sesuai dengan spesifikasi

2 Perbedaan antara volume pekerjaan rencana dengan pelaksanaan

3 Pekerja mengabaikan prosedur K3 dalam pelaksanaan proyek / kecelakaan kerja

$4 \quad$ kualifikasi teknik dan manajerial yang buruk dari personil dalam organisasi kerja kontraktor

Review BQ dan Reschedule schedule pelaksanaan

Review BQ dan spesifikasi pekerjaan

Review volume pekerjaan pada BQ

Briefing K3 pada setiap memulai kegiatan diproyek, evaluasi pelaksanaan K3 diproyek dan koordinasi pihak manajemen proyek dengan pekerja mengenai $\mathrm{K} 3$

Penggantian personil yang lebih kompeten dan lebih sering melakukan koordinasi

D Aspek Sumber Daya

1 Keterlambatan pembayaran termin oleh owner

2 jumlah pekerja yang kurang memadai

3 alat/peralatan kerja yang tidak memadai

4 kurangnya keahlian dan keterampilan kerja pada pekerja

5 Tidak tersedianya bahan sesuai kebutuhan

E Aspek Lingkungan

1 Terjadinya hal-hal yang tidak terduga (bencana alam, kebakaran)

2 Adanya huru-hara atau kerusuhan

3 libur kegiatan adat diluar jadwal proyek

Melakukan koordinasi dengan pihak owner

Menerapkan kerja lembur agar proyek berjalan sesuai schedule atau menambah pekerja

Mengganti alat/peralatan dengan model terbaru dan Menambah peralatan

Mengganti pekerja dengan yang memiliki keahlian yang dibutuhkan

Melakukan order lebih awal, evaluasi mekanisme pengorderan, perhitungan bahan dengan lebih teliti

Review schedule, RAB dan melakukan rapat koordinasi

Melakukan koordinasi dengan pihak terkait dan menyesuaikan schedule kerja lebih lajut

Koordinasi antara pihak manajemen dan pekerja dan menambah tenaga 


\section{SIMPULAN DAN SARAN}

\subsection{Simpulan}

Berdasarkan analisis yang telah dilakukan maka dapat ditarik kesimpulan sebagai berikut:

1. Diperoleh 5 variabel faktor risiko keterlambatan proyek The Himana Condotel yaitu dari aspek perencanaan, aspek Dokumen pekerjaan dan kontrak, aspek pelaksanaan, aspek sumber daya dan aspek lingkungan. Dari kelima aspek tersebut diuraikan menjadi 48 uraian risiko.

2. Risiko dominan yang diperoleh berdasarkan presentase tingkat risiko diperoleh tingkat risiko tinggi dengan nilai 36\%. Dari kelima aspek variable faktor risiko keterlambatan seluruhnya terdapat risiko tinggi dan uraian risiko yang memiliki tingkat risiko tinggi ada sebanyak 17 uraian risiko.

3. Hal-hal yang disarankan untuk mitigasi risiko dominan yang dilakukan adalah dengan lebih banyak berkoordinasi antara pihak-pihak yang terkait, penyusunan penjadwalan dan perencanaan secara lebih terperinci, teknis pelaksanaan dilapangan khususnya dokumen pekerjaan baik BQ, kontrak, RKS lebih diperhatikan, meningkatkan ketepatan pelaksanaan pekerjaan sesuai dengan yang telah direncanakan.

\subsection{Saran}

Dari hasil penelitian dan simpulan yang ditarik hal yang dapat disarankan adalah:

1. Pihak kontraktor diharapkan dapat melaksanakan proyek konstruksi sesuai dengan jadwal yang telah direncanakan dengan lebih banyak mengevaluasi faktor-faktor penyebab keterlambatan pada pelaksanaan proyek sehingga mampu menanggulangi risiko keterlambatan di masa depan.

2. Pada penelitian selanjutnya untuk dapat lebih banyak mengidentifikasi variable faktor keterlambatan agar memperoleh informasi mengenai faktor keterlambatan yang lebih variatif.

\section{DAFTAR PUSTAKA}

Ervianto, W. I. (2005). Manajemen Proyek Konstruksi (Edisi Revi). Yogyakarta: ANDI. 
Flanagan, R., \& Norman, G. (1993). Risk Management and Construction. London: Blackwell Science.

Husen, A. (2011). Manajemen Proyek. Yogyakarta: ANDI.

Kerzner, H. (2001). Project Management (Seventh Ed). New York: Jhon Wiley \& Sons, Inc.

Labombang, M. (2011). Manajemen Risiko Dalam Proyek Konstruksi. SMARTek, 9(1), 39-46.

Norken, I. N., Astana, I. N. Y., \& Manuasri, L. K. A. (2012). Manajemen Risiko pada Proyek Konstruksi di Pemerintah Kabupaten Jembrana. Jurnal Ilmiah Teknik Sipil, 16(2), 202-211.

Nurlela, \& Suprapto, H. (2014). Identifikasi dan Analisis Manajemen Risiko pada Proyek Pembangunan Infrastruktur Bangunan Gedung Bertingkat. Jurnal Desain Konstruksi, 13(2), 114-124.

Proboyo, B. (1999). Keterlambatan Waktu Pelaksanaan Proyek: Klasifikasi dan Peringkat dari penyebabpenyebabnya. Dimensi Teknik Sipil, 1(1), 49-58.

Putera, I. G. A. A., Harmayani, K. D., \& Putra, I. G. I. (2019). Manajemen Risiko Pelaksanaan Pembangunan Sistem Pengolahan Air Limbah Terpusat Kota Denpasar Tahap II (Jaringan Air Limbah Pedungan). Jurnal Spektran, 7(1), 42-50.

Renaldhi, M. R. (2014). Analisis Risiko Keterlambatan Proyek Pembangunan Tangki X di TTU-Tuban (Studi Kasus: PT. Pertamina UPMS V). Institut Teknologi Sepuluh Nopember Surabaya.

Rumimper, R. R., Sompie, B. F., \& Sumajouw, M. D. J. (2015). Analisis Risiko pada Proyek Konstruksi
Perumahan di Kabupaten Minahasa Utara. Jurnal Ilmiah Media Engineering, 5(2), 381-389.

Sukirno. (2015). Analisis Resiko Waktu Di Proyek Konstruksi Studi Kasus Proyek Ampuh Pressure Maintenence Di Duri, Riau. Rekayasa Sipil, 9(3), 201-210.

Wirawan, I. G. K., Sudarsana, I. K., \& Purbawijaya, I. B. N. (2015). Manajemen Risiko Pada Proyek Konstruksi Dengan Metode Fast Track Studi Kasus Proyek Quinci Villas dan Putri Naga Komodo. Jurnal Spektran, 3(2), 29-36. https://doi.org/10.24843/SPEKTRA N.2015.v03.i02.p04

Yuliana, C. (2017). Manajemen Risiko Kontrak Untuk Proyek Konstruksi. Rekayasa Sipil, 11(1), 9-16. https://doi.org/10.21776/ub.rekayasa sipil.2017.011.01.2 